Research Article

\title{
Formation Mechanism and Stability Analysis of the Hejia Landslide
}

\author{
Hao Zhang $\left(\mathbb{D}\right.$, ${ }^{1,2}$ Zaiqiang $\mathrm{Hu}\left(\mathbb{D},{ }^{1}\right.$ Xingzhou Chen $\mathbb{D D}^{3},{ }^{3}$ and Hongru Li ${ }^{1}{ }^{1}$ \\ ${ }^{1}$ School of Civil Engineering and Architecture, Xi'an University of Technology, Xi'an 710048, China \\ ${ }^{2}$ Power China Northwest Engineering Corporation Limited, Xi'an 710065, China \\ ${ }^{3}$ School of Architecture and Civil Engineering, Xi'an University of Science and Technology, Xi'an 710054, China
}

Correspondence should be addressed to Zaiqiang Hu; huzq@xaut.edu.cn

Received 9 November 2021; Accepted 4 December 2021; Published 26 December 2021

Academic Editor: Bingxiang yuan

Copyright ( $\odot 2021$ Hao Zhang et al. This is an open access article distributed under the Creative Commons Attribution License, which permits unrestricted use, distribution, and reproduction in any medium, provided the original work is properly cited.

The existing research data show that, after reservoir impoundment, due to the repeated rise and fall of water level and water-rock interaction, the mechanical parameters of landslide are reduced, which will have an adverse effect on the stability of landslide. Therefore, sufficient attention must be paid to the stability of slope after reservoir impoundment. Hejia landslide is the largest landslide near the bank of Miaojiaba hydropower station, and its stability plays an important role in the normal operation of the hydropower station. Through field investigation and analysis of regional geological conditions, it is concluded that Hejia landslide is a large-scale landslide, through long-term sliding-bending deformation; it is generated from the external hard rock with thick layers and sliding zone for layered soft rock; the formation mechanism of landslide is as follows: (1) high-steep and hard-soft layered slope is the slope structure condition that caused the large landslide; (2) the existence of thick soft rock belt provides material conditions for the formation of slip surface; (3) certain air conditions provide displacement space for the separation and disintegration of the sliding body, and the landslide is stable at present. Numerical analysis results show that reservoir impoundment will adversely affect the stability of landslide. In order to ensure the normal operation of power station, certain engineering measures must be taken to treat Hejia landslide. After taking measures, years of monitoring data show that the deformation of Hejia landslide tends to be stable, and the current operation is normal, indicating that the engineering treatment measures are reasonable and feasible.

\section{Introduction}

Over the past 20 years, most hydropower stations in China have been constructed in the western mountains and valleys with harsh natural conditions, poor geological conditions, and broken rock masses. In the reservoir area, unfavorable geologic bodies such as landslide and toppling mass are widely distributed. If improperly treated, they will have an adverse effect on the construction and operation of the hydropower stations. There were landslides in the Longyangxia Hydropower Station [1], Lijiaxia Hydropower Station [2], Manwan Hydropower Station [3], and Laxiwa Hydropower Station [4] after their completion and operation. Although these landslides did not cause harm to the major buildings, the repair was expensive. Therefore, during the construction of hydropower stations, we need to pay close attention to the slope safety.

Previous studies worldwide have focused on how the changes of reservoir water level will influence the landslide. Yi et al. [5] investigated the formation mechanism of Tang Gudong landslide. Dai [6] studied the deformation and the loss of stability of the large landslide in Ou'tang near the Three Gorges Reservoir. Yuan et al. [7] established a multistage filling slope model by using PLAXIS finite element software and conducted sensitivity analysis and stability analysis on the slope under different working conditions. Guo [8], Yu [9], and Wei [10] studied the deformation and stability of rock slope under water level fluctuations. Yuan et al. [11] proposed a parameter index to quantify the effect of residual soil reinforcement based on the equivalent 
confining pressure, which can provide reference for the safe operation of retaining wall and slope. $\mathrm{Wu}$ [12] studied the deformation of the landslide in the upper reaches of the Minjiang River. Xiao et al. [13] conducted a model test to study slope deformation under rainfall and the variation of reservoir water level. Based on the theory of rainfall infiltration, Yuan et al. [14] established the surface infiltration model of multilevel filled slope by using the SEEP/W module of GeoStudio. The influence of the change of the rainfall conditions on the VWC and PWP was considered. He et al. [15] analyzed the stability of slope under the change of water level. Yang et al. [16] studied the seepage lag of landslide accumulation with the fluctuation of reservoir water level. According to previous studies, the water storage of the reservoir may threaten the slope stability because it causes the physical and chemical reactions in the slope, deteriorates the physical and mechanical properties of the rock and soil bodies, and destroys the original seepage field and the stress field of the slope. To control flood and generate power, large hydropower stations have to frequently change the water level of the reservoir during the operation, which greatly affects the slope stability.

This paper studied the formation mechanism of the landslide in the reservoir area of a hydropower station in southwest China. Backed by results from the field survey and analysis of regional geology, it carried out a numerical analysis of the landslide stability to provide basis for engineering design.

\section{Overview of the Landslide}

2.1. Topography of the Landslide. The hydropower station is located in a canyon area of western China, where landslides and deformation bodies extremely develop. The largest landslide is situated on the left bank, approximately $600 \mathrm{~m}$ upstream of the dam site. It can be categorized as a super large landslide as its longitudinal length is $80 \sim 900 \mathrm{~m}$ and its horizontal width is $360 \sim 400 \mathrm{~m}$. The diamond-shaped landslide has an area of $0.34 \mathrm{~km}^{2}$, with average thickness longer than $57 \mathrm{~m}$ and a volume of $2,350 \times 10^{4} \mathrm{~m}^{3}$. The slope was gentle in the upper part and steep in the lower part, with angles of $24 \sim 30^{\circ}$ in the upper, $34^{\circ}$ in the middle, and $41^{\circ}$ in the lower. There are two gullies developed in the sliding mass without cutting through it. They are $550 \sim 600 \mathrm{~m}$ long, 20 40 $\mathrm{m}$ deep, and $2 \sim 6 \mathrm{~m}$ wide at the bottom. The leading edge, with an elevation of $800 \sim 810 \mathrm{~m}$, was $90 \sim 100 \mathrm{~m}$ above the river level; the trailing edge, with an elevation of $1,450 \mathrm{~m}$, had an obvious $200 \mathrm{~m}$ high triangular rupture wall, as shown in Figure 1.

\subsection{Structural Characteristics of the Landslide}

2.2.1. Lithology and Structure of the Landslide. The Hejia landslide develops in Changchengian Bikou Group metamorphic rocks interbedded with tuff and slate. The field survey suggests that the trailing edge of the landslide and the downstream area consist of argillite; the upstream boundary is dominated by metamorphic tuff and the leading edge of the landslide comprises thick-layered metamorphic tuff

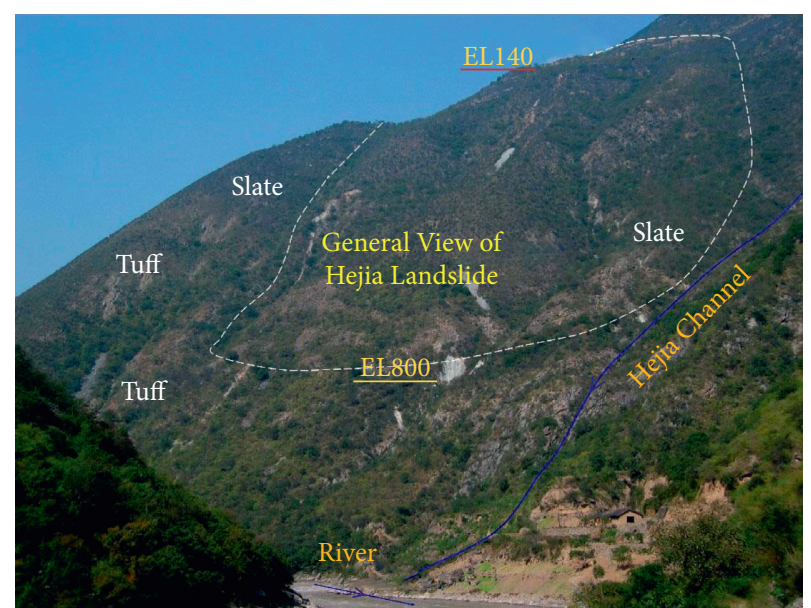

Figure 1: General view of the Hejia landslide.

(Figure 2). Figure 2 shows that the upper sliding bed and the rock mass beneath it consist of argillite, the lower surface of the landslide comprises tuff, and the lower sliding bed is dominated by argillite.

2.2.2. Composition of the Landslide Surface. According to the field survey, the composition of the landslide surface is as follows:

(1) The trailing edge and the surface layer consist of loess.

(2) The section in the trailing edge consists of disintegrated slate gravel and rock. The downstream sliding mass contains slate gravel and rock with plate and sheet shapes.

(3) The upstream boundary comprises massive tuff rocks.

(4) The rock-layer reverse in the leading edge mainly contains small slate gravel as well as mud-like slate or sheets of slate. They are formed by the rolling up of slate near the slip zone.

(5) The sliding mass had partition characteristics and can be divided into the downstream partition (partition II) and the upstream partition (partition I). The partition map of the Hejia landslide is shown in Figure 3. Composed of slate gravel, partition I is $2 \sim 3$ times wider than partition II, which mainly contains tuff and partly disintegrated slate.

2.2.3. Internal Structure of the Sliding Mass. Figure 4 is the typical geological profile of the Hejia landslide. The sliding mass can be categorized into 6 zones based on differences in composition.

(i) The loess zone on the surface of the slip band is mainly distributed in the gentle slope of the trailing edge at elevations higher than $1,200 \mathrm{~m}$.

(ii) The gravel, rock, and layered rock zone are in the shallow surface of the sliding mass. This zone is 


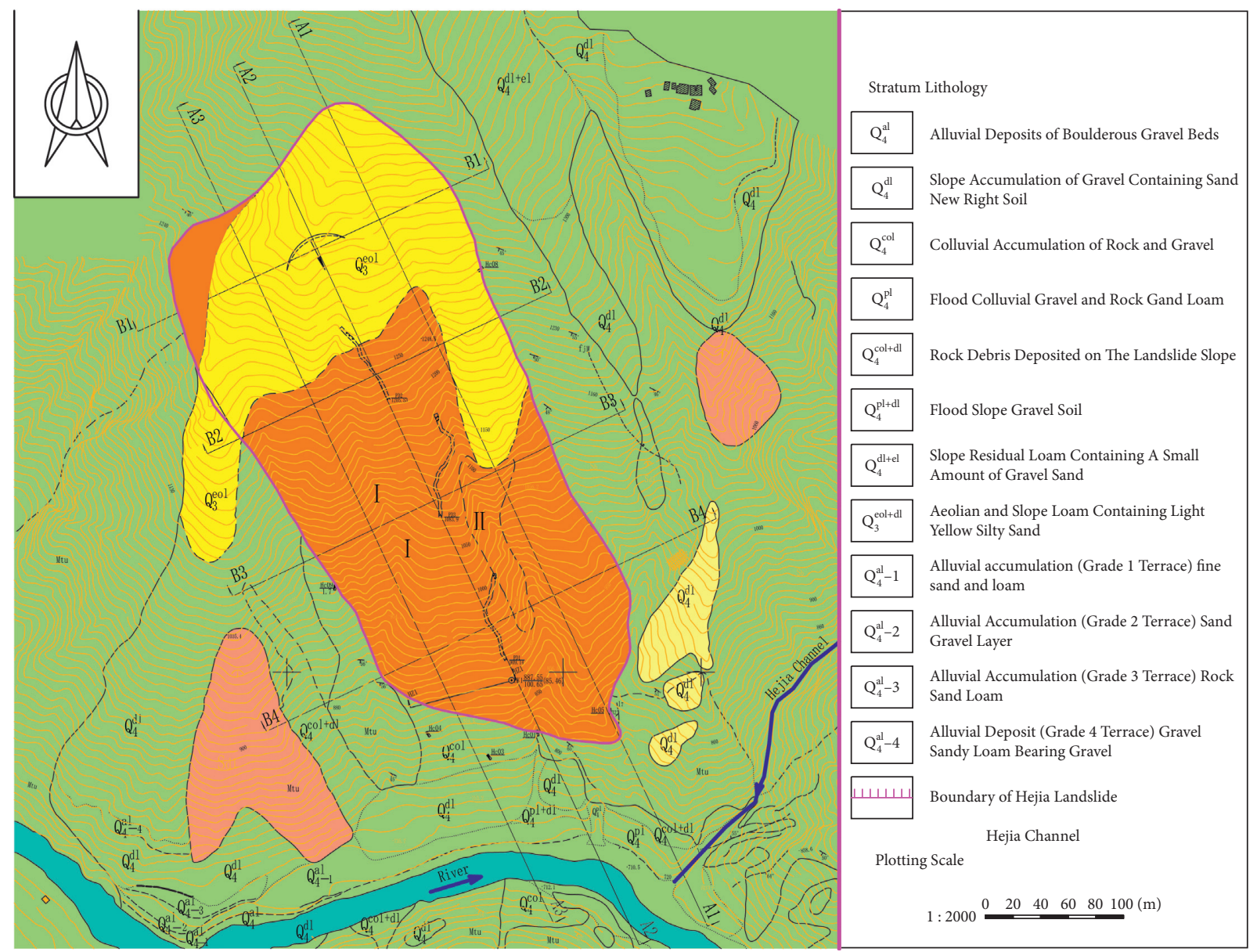

Figure 2: Geological plan of the Hejia landslide.

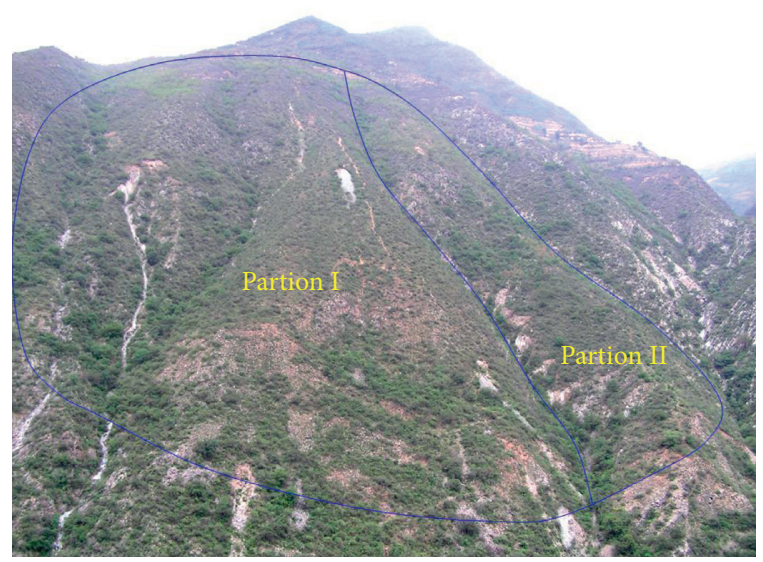

Figure 3: Partition map of the Hejia landslide.

mainly distributed in the shallow surface of the sliding mass below 1,200 m elevation. It is composed of gravel and rock formed by the landslide. The zone at the middle part of the sliding mass is the most deformed. Although the patent rock, metamorphic tuff, and arenaceous argillite have decomposed into gravel and rock, the sequence structure of primary rock is still visible (Figure 5). The zone at the front part of the sliding mass consists mainly of badly decomposed primary rock, with much narrow diameters of $0.3 \sim 1 \mathrm{~m}$ and more fine grain materials can be found (Figure 6).

The lateral gullies of the partition II cut deep inside the sliding mass. Some of the gullies even cut through the sliding mass. The materials exposed on the gully bank are layered metamorphic tuff and arenaceous argillite. Their size depends on the thickness of the single layer of the parent rock. These rocks accumulate and are supported on stilts. Compared with the occurrence of the bedrock, the layered rock in the partition II has changed more. The change was caused by landslide movement. When the landslide occurred, rocks cut by the bedding plane and the structural plane in the sliding mass had uncoordinated displacement, so they separated or squeezed each other. As a result, the occurrence of layered rock in the partition II changed more (Figure 7).

(iii) The zone of residual layered rocks and large rocks is distributed in the middle and shallow parts of the sliding mass. This zone is composed of metamorphic tuff gravel and rock. As revealed by the adits PD1 and PD3, the horizontal thickness of zone is $60 \sim 65 \mathrm{~m}$. The 


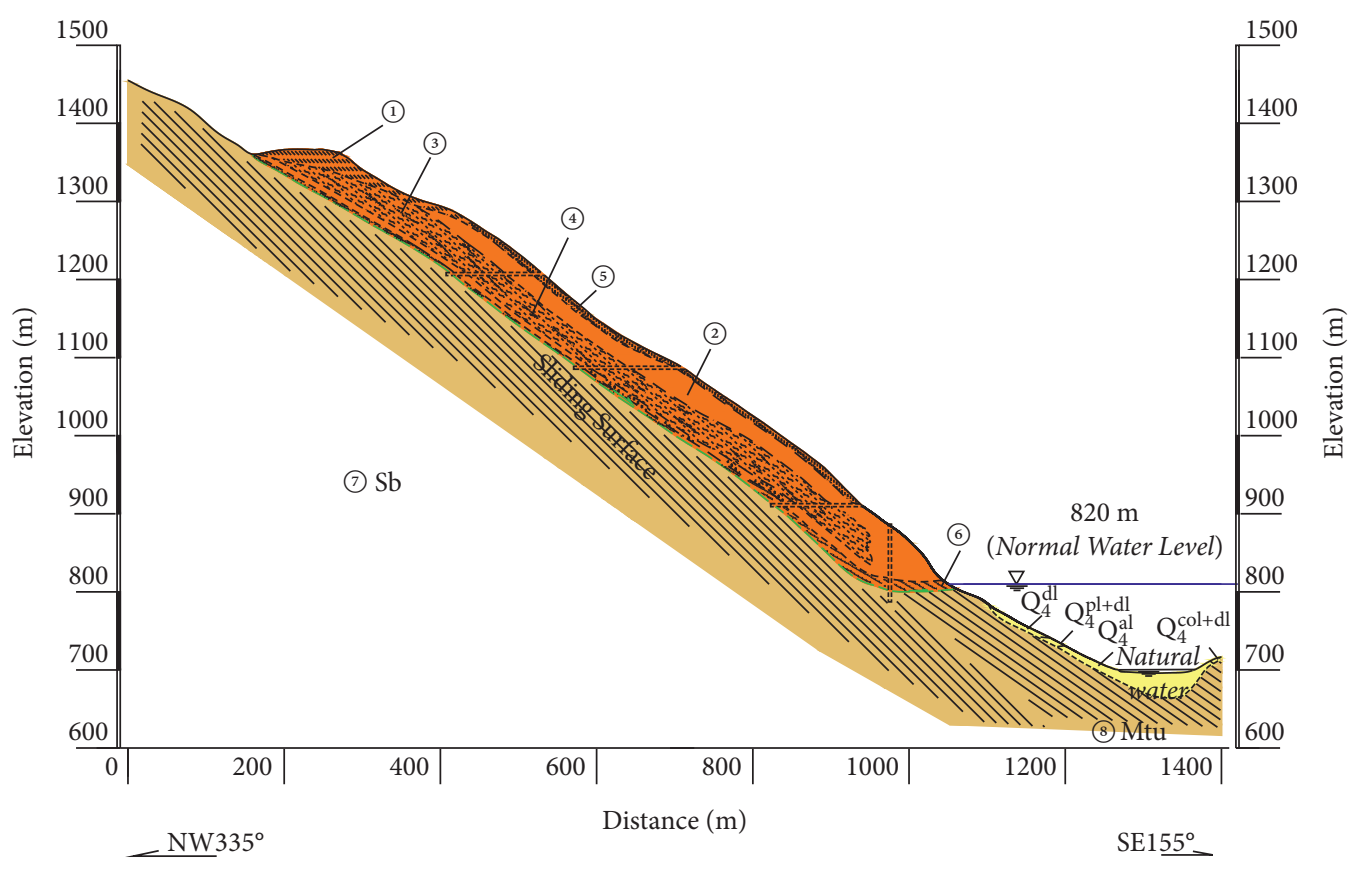

(1) Loess

(2) Middle and shallow layer stone

(3) Middle and Deep Sliding Mass

(4) Deep Sliding Body Deformed And Folded By Slate

(5) Slope Accumulation of Gravel Containing Sand New Right Soil

(6) Slip Band

(7) Sandy Argillaceous Slate

(8) Metamorphic Tuff

Figure 4: Typical geological profile of the Hejia landslide.

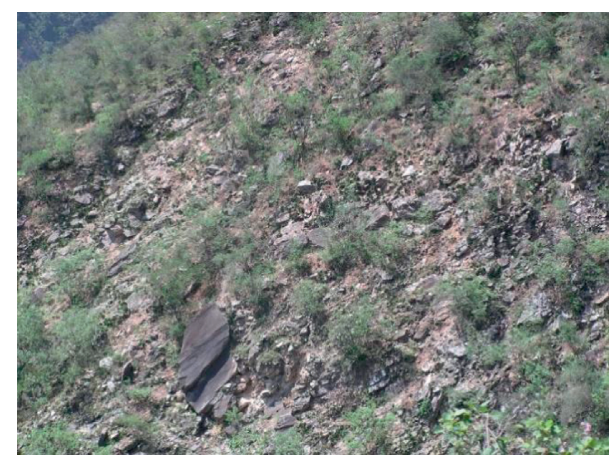

FIGURE 5: Gravel and rock retaining the sequence structure of primary rock in partition I at $960 \sim 1,200 \mathrm{~m}$.

parent rock is gray-green medium-thick metamorphic tuff. The diameter of residual layered rocks and large rocks in the zone varies greatly from $20 \sim 30 \mathrm{~cm}$ to over $3 \mathrm{~m}$. Most rocks are about $1 \mathrm{~m}$. The zone has a loose structure without fine-grained material filling inside.

(iv) The middle and deep parts of the landslide mass still retain the layered structure. This zone is about $40 \sim 45 \mathrm{~m}$ thick and the single layer of the residual rock is $30 \sim 40 \mathrm{~cm}$ thick. The dip direction of this zone is $200^{\circ} \sim 225^{\circ}$, close to that of the bedrock.

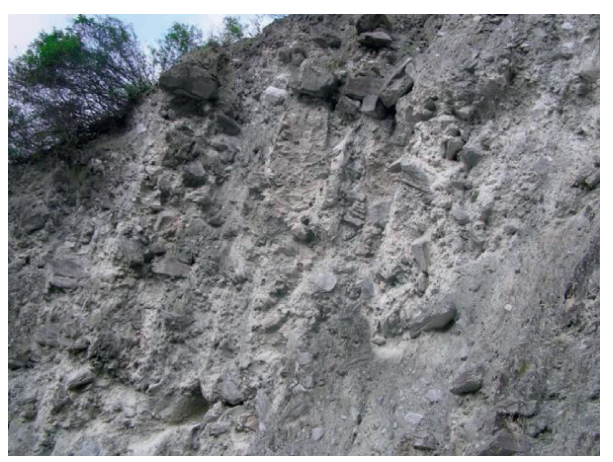

FIgURE 6: Composition of the front of the sliding mass in partition I.

However, the dip angle of the rock stratum has changed $40^{\circ} \sim 71^{\circ}$, which is a large variation. Although the layered remnants of the parent rock are relatively complete, the zone still contains the characteristics of displacement, dislocation, fracture, and separation along the bedding plane and the structural plane.

(5) The highly folded zone of argillite: the first 5 10 m of the zone mainly consists of breccia and rock dust. There are also some scattered gravel and rock and a 


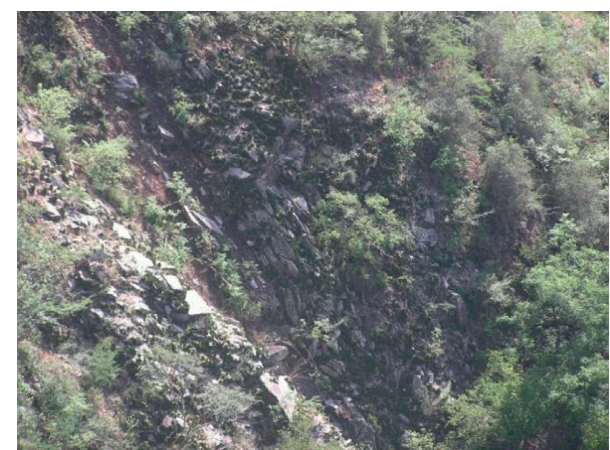

FIGURE 7: Material composition of the sliding mass in partition II.

few magenta argillaceous materials. The lower part is a strongly crumpled stratum composed of arenaceous and argillaceous slate. It has developed asymmetric recumbent folds, with local ruptures. The stratum is tightly compressed without any fracture or overhead and the axial plane dips inside the slope.

(6) The slip zone: this zone is about $6 \sim 9 \mathrm{~m}$ thick and is composed of grayish white rock dust and yellow dark brown argillaceous material. It also contains breccia, which is compact, wet, and sandy, with a particle diameter of $0.3 \sim 1 \mathrm{~cm}$. The sliding surface is $133 \mathrm{~m}$ away from the adit PD1 and $162 \mathrm{~m}$ away from the adit PD3. The sliding bed is composed of finegrained tuffaceous slate. The single rock layer is $2 \sim 3 \mathrm{~cm}$ thick and the rock structure is relatively intact, with an occurrence of $191 \sim 202 \angle 43 \sim 52^{\circ}$, the same as the sliding surface.

Different parts of the slip zone revealed by the exploration adits have good correspondence in occurrence, location, thickness, and composition properties. Therefore, it can be concluded that the slip zone has a unified main sliding surface composed of a single rock stratum (interbedded and compressed). Moreover, as the branch sections in the three adits at different elevations show almost the same characteristics of the main sliding mass, and the five zones of different materials, from the surface to the center, have good correspondence in terms of extension, direction, thickness, and state, the possibility of multilevel sliding masses existing inside the main sliding mass can be ruled out.

\subsection{Deformation Characteristics of the Landslide}

2.3.1. Deformation Characteristics of the Trailing Edge. There is a $20^{\circ}$ gentle slope in the trailing edge of the Hejia landslide. The wide slope is covered by $10 \sim 20 \mathrm{~m}$ thick loess. According to the field survey, this slope does not have step-like terrain, indicating that the trailing edge has never been greatly deformed in history. This is confirmed by the lush vegetation and tall trees. The sliding mass has a length of over $800 \mathrm{~m}$. Controlled by the residual layered structure of the sliding mass, the slope surface is roughly consistent with the residual layered surface. The field survey showed that the slope was relatively straight without large steps.
2.3.2. Deformation Characteristics of the Sliding Mass. The sliding mass has a length of over $800 \mathrm{~m}$. Controlled by the residual layered structure of the sliding mass, the slope surface is roughly consistent with the residual layered surface. If there was a large deformation, a step-like terrain would appear. The field survey showed that the sliding mass was relatively straight without large steps.

\subsubsection{Deformation Characteristics near the Sliding Zone.} For exploration, the adits of the Hejia landslide were first excavated in 1990. The field survey in 2009 suggested that the main adits retained their original shape without any supports [17]. This suggested that the sliding mass composed of slate near the sliding zone had good integrity and tightness.

\section{Analysis of the Landslide Formation}

\subsection{Hard, Soft, High, and Steep Layered Slope Provided} Structural Conditions for the Preparation of the Sliding Mass. The sliding mass of the Hejia landslide was over $800 \mathrm{~m}$ in length. To support such a long sliding mass, the rock mass must have a thick layer and high mechanical parameters. The deformation body of Bawang Mountain is situated $5 \mathrm{~km}$ away from the upstream of the Ertan Dam on the Yalong River. The over $900 \mathrm{~m}$ high slope comprises medium-thick limestone interbedded with clay rock. Many experts and engineers believe that it belongs to the sliding-bending (buckling) deformation failure. As the rock stratum is thick and high in modulus, it serves a stiff "plate" to hold the large slope, resulting in the great height and bending (buckling) depth of the slope.

The exterior of the Bawang Mountain slope consists of thick-layered limestone and its interior is interbedded with clay rock. The structure and properties of the Bawang Mountain slope are similar to those of the Hejia landslide, which has thick-layered hard tuff outside and extremely thin argillite inside. Moreover, the slope of Bawang Mountain is as high as the Hejia landslide. Thus, the thick-layered tuff outside the slope of the Hejia landslide provided the major structural condition for supporting the sliding mass.

\subsection{Thick-Layered Weak Rock Zone Provided Material Conditions for the Formation of the Sliding Surface. The exterior of the Hejia landslide was made of thick and hard tuff and the $110 \sim 120 \mathrm{~m}$ area inside the sliding mass consisted of extremely thin layers of argillite and many weak interbeds. The thin layers and weak interbeds constituted a low-strength bedding surface within the slope. The surface was prone to large shear deformation (or plastic deformation) along the weak zone under slope stress. Long-time shear creep will lead to large plastic deformation of the slope and trigger a landslide.}

3.3. Critical Conditions Provided Displacement Space for the Separation and Disintegration of the Sliding Mass. There was a large gully downstream of the Hejia landslide and there were several other gullies roughly parallel to it. They were 
developed along the argillite or interbedded compressed zone in the layered rock mass. Figure 8 shows that these large gullies served as the downstream boundary of the Hejia landslide, forming conditions of downstream part being laterally separated from the slope. The upstream boundary of the landslide was comprised mainly of metamorphic tuff, with small gullies, thus having insufficient critical conditions. Moreover, away from the downstream boundary, there was a ridge stretching along the inclined direction of the rock layer. The ridge might block the slide and the large gullies in the lower right of the landslide (downstream boundary) provided conditions for a slight change of direction of the landslide displacement when the slide was blocked.

\section{Soil Properties of the Sliding Zone of the Landslide}

4.1. Physical Indicators of the Sliding Zone Soil. The sliding zone soil was exposed in several exploration adits of the Hejia landslide. The undisturbed samples were collected at multiple points, and their physical indicators were measured on site and indoor, respectively. The results are shown in Table 1.

A particle size analysis test of the sliding zone soil was conducted. The results showed that the content of debris and gravel $(\geq 0.075 \mathrm{~mm})$ was $60.8 \%$, and the content of clay and silt $(<0.005 \mathrm{~mm})$ was $39.2 \%$. The results are shown in Table 2.

4.2. Fitting Test of Soil Stress-Physical Properties in Sliding Zone of Hejia Landslide. In this study, several groups of gravity fitting compaction tests were carried out. The process method was to make the sliding zone soil into a near-liquid sample first and then carry out the stress-compaction test. The void ratio at various pressures obtained in the test is shown in Table 3.

The correlation formula between pressure and void ratio obtained from the table is as follows:

$$
e=-0.0342 \ln (P)+0.548(r=0.999) \text {. }
$$

By using element method, formula (1) of the normal stress caused by the dead weight of the sliding body on the sliding surface can be calculated. The normal stress obtained in different sections of the sliding surface is shown in Figure 9. It is shown that the normal stress in the sliding zone of Hejia landslide is relatively small in the upper part and gradually increases in the middle part, and the maximum normal stress in the lower part can reach 3.4-3.6 $\mathrm{MPa}$ under the action of the dead weight of the overlying sliding body.

The pressure-void ratio relationship established by the normal stress and gravity compaction tests can help us understand the void ratio in different areas of the slip surface, and then the corresponding water content can be calculated by using the relationship between saturation, void ratio, and specific gravity value.
4.3. Indoor Sliding Soil Strength Test. Shear tests were carried out on samples of sliding zone soil with different densities, water content, and void ratio in laboratory to establish the relationship between the void ratio, water content, and friction coefficient and cohesion of sliding zone soil. The calculation results are shown in Table 4 .

According to the analysis of multiple groups of test results, the soil in the sliding zone of Hejia landslide is composed of more coarse particles, with debris accounting for $60.8 \%$, and the particle size is mainly $2-20 \mathrm{~mm}$, and the clay content only accounts for $17.3 \%$. Therefore, the change of water content has less influence on the friction coefficient F value. The experimental results show that the $f$ value varies from 0.54 to 0.63 in the process of water content increasing from $8.4 \%$ to $17.5 \%$, and most of the $f$ value ranges from 0.58 to 0.60 . The cohesion $c$ value decreases with the increase of water content. The correlation analysis between water content and cohesion was conducted, and the relationship curve between cohesion $\mathrm{C}$ and water content $\mathrm{W}$ was obtained. The relevant formula is as follows:

$$
\ln (c)=7.857-0.362 * w(r=0.995) .
$$

According to Section 4.2 of this paper, water content is calculated first, and then cohesion $\mathrm{C}$ can be calculated according to formula (2). The calculation results are shown in Table 5.

4.4. Strength Test and Results Analysis Indicators of the Sliding Zone Soil. Remolded consolidated quick shear tests of five groups of the sliding zone soil samples were conducted, the test results are shown in Table 6 . With $f=0.606, c=118 \mathrm{kPa}$ above water and with $f=0.485, c=36 \mathrm{kPa}$ under water ( $f$ for friction coefficient and $c$ for cohesive force).

\section{Determination and Stability Analysis of the Landslide Physical Parameters}

5.1. Calculation Parameters of the Landslide. The calculation parameters of the landslide are shown in Table 7.

5.2. Calculation Condition of the Landslide. Four calculation conditions were considered for the landslide calculation as shown in Table 8.

5.3. Overall Stability Calculation Results of the Landslide. The stability of the landslide under each calculation condition was analyzed with the GeoStudio, a slope stability analysis software. The software's built-in SEEP/W module can automatically import the seepage calculation results for stable analysis. Table 9 shows the results of the landslide stability under different working conditions. The safety factor of calculation condition 1 is 1.337 , indicating the landslide was in a stable state, the same as the field survey's result. After the slope is saturated because of the water storage of the reservoir, its mechanical parameters are reduced, so the safety factor of the calculation condition 2 declines to 1.231 , which is in line with the current general 


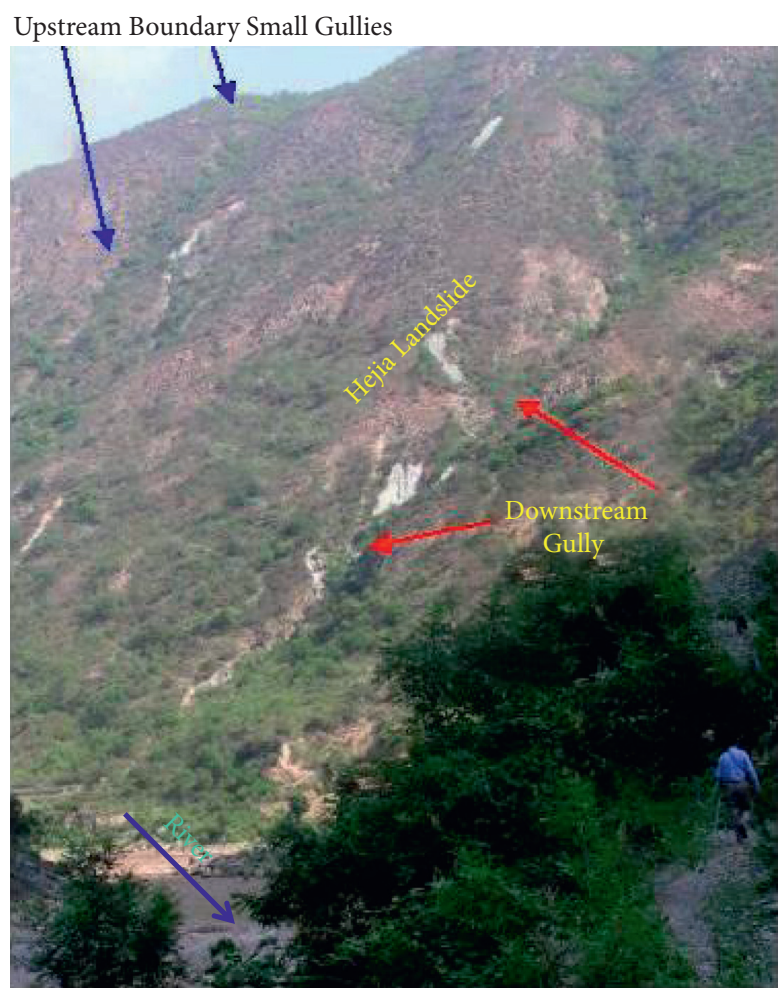

FIGURE 8: Downstream gully and downstream boundary of the Hejia landslide.

TABle 1: Physical indicators of the sliding zone soil.

\begin{tabular}{lcccccccc}
\hline No. & $\begin{array}{l}\text { Density } \\
\left(\mathrm{g} / \mathrm{cm}^{3}\right)\end{array}$ & Water content $(\%)$ & Proportion & Dry density $\left(\mathrm{g} / \mathrm{cm}^{3}\right)$ & Void ratio & Saturation $(\%)$ & Plastic limit & Liquid limit \\
\hline 1 & 2.16 & 10.52 & 2.77 & 1.95 & 0.42 & 0.70 & 15.8 \\
2 & 2.19 & 9.97 & 2.79 & 1.99 & 0.39 & 0.69 & 15.8 \\
3 & 2.12 & 9.01 & 2.75 & 1.94 & 0.41 & 0.60 & 16.2 \\
4 & 2.14 & 9.08 & 2.78 & 1.96 & 0.42 & 0.61 & 24 & 16.2 \\
Average value & 2.15 & 9.65 & 2.77 & 1.96 & 0.41 & 0.65 & 23.9 \\
\hline
\end{tabular}

TABle 2: Results of the particle size analysis test of the sliding zone soil.

\begin{tabular}{lccccc}
\hline No. & $>20 \mathrm{~mm}$ & $20 \sim 2 \mathrm{~mm}$ & $2 \sim 0.075 \mathrm{~mm}$ & $0.075 \sim 0.005 \mathrm{~mm}$ & $<0.005 \mathrm{~mm}$ \\
\hline 1 & 8.0 & 30.1 & 22.0 & 22.5 & 21.4 \\
2 & 8.3 & 31.5 & 21.6 & 21.9 & 18.0 \\
Average value & 8.2 & 30.8 & 21.8 & 17.2 \\
\hline
\end{tabular}

TABLE 3: Gravity fitting compression test pressure and porosity ratio.

\begin{tabular}{lcccccccccc}
\hline Pressure $(\mathrm{kPa})$ & 0 & 12.5 & 25 & 50 & 100 & 200 & 400 & 600 & 1600 & 3200 \\
\hline Void ratio & 0.56 & 0.46 & 0.44 & 0.41 & 0.39 & 0.37 & 0.35 & 0.32 & 0.30 & 0.27 \\
\hline
\end{tabular}

law. In the event of normal water level + earthquake, the safety factor drops to 1.086. After the slope toe collapsed after the water storage of the reservoir, the safety factor decreases but is still above the stable state of 1.0.

5.4. Stability Evaluation of the Landslide. According to the research of Section 3 and the overall stability calculation results of this section, the Hejia landslide was a super large-scale buckling-type landslide caused by long-term sliding and bending deformation of medium-steep and layered rock mass with thicklayered hard tuff outside and a sliding zone of layered soft rock, and it was an incompletely disintegrated landslide. Under natural water level, normal water level $800 \mathrm{~m}$, and normal water level $800 \mathrm{~m}$ (collapsed bank $30 \mathrm{~m}$ wide), it was in a stable state. 


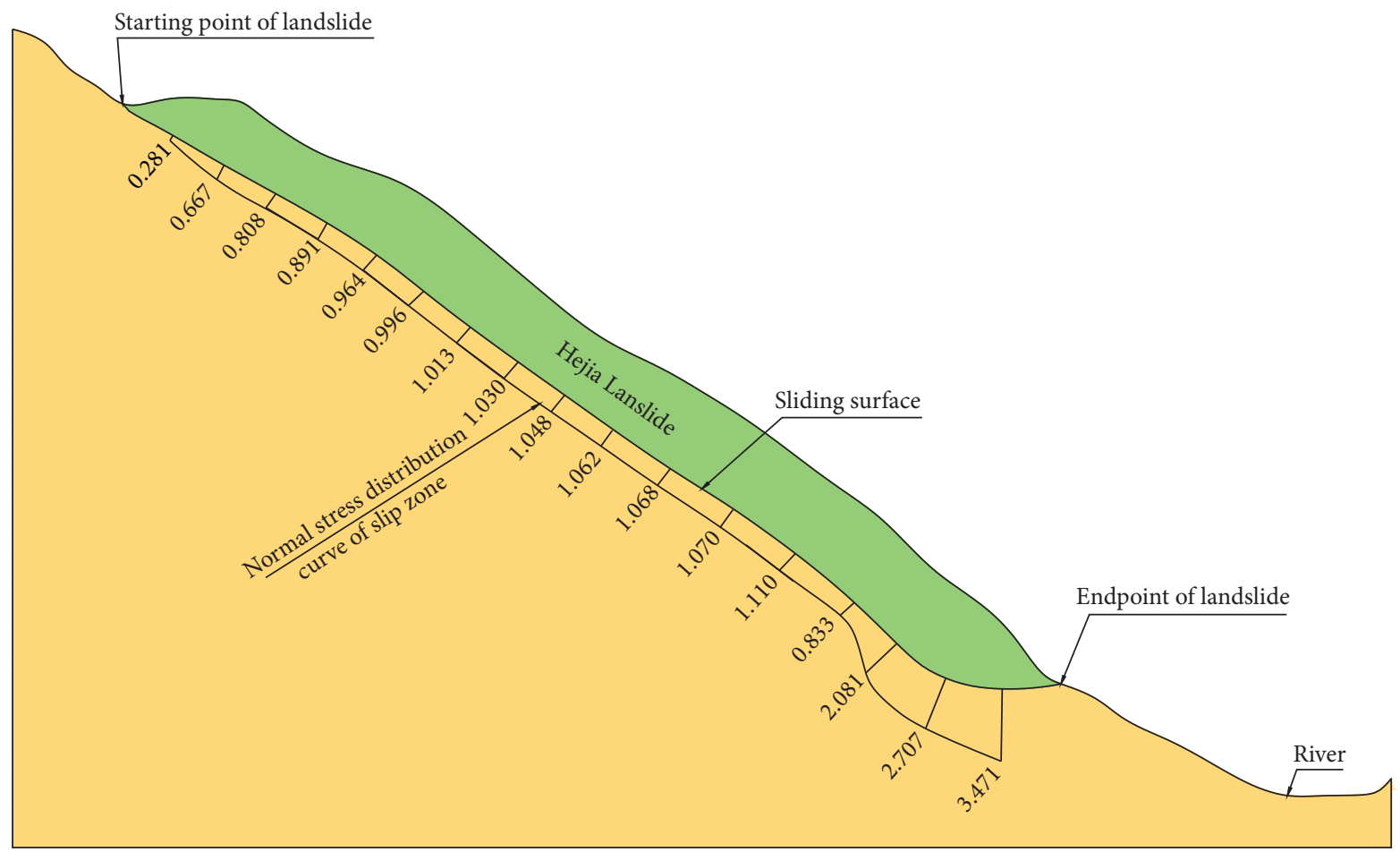

FIGURE 9: Calculation results of normal stress in slip zone of Hejia landslide.

TABLE 4: Strength index of soil in slip zone of Hejia landslide under different water content.

\begin{tabular}{lccc}
\hline Number of samples & Water content $(\%)$ & Friction coefficient & Cohesion $(\mathrm{kPa})$ \\
\hline 1 & 8.4 & 0.54 & 124 \\
2 & 10.2 & 0.58 & 42 \\
3 & 12.1 & 0.55 & 35 \\
4 & 13.1 & 0.60 & 26 \\
5 & 15.0 & 0.60 & 13 \\
6 & 16.3 & 0.63 & 7 \\
7 & 17.5 & 0.62 & 2 \\
\hline
\end{tabular}

TABLE 5: C values of representative section of the sliding surface of Hejia landslide.

\begin{tabular}{|c|c|c|c|c|c|}
\hline Distance $(\mathrm{m})$ & Spacing $(\mathrm{m})$ & Normal stress $\mathrm{P}(\mathrm{MPa})$ & Void ratio & Water content $(\%)$ & $\begin{array}{c}\text { Cohesion } \\
(\mathrm{kPa})\end{array}$ \\
\hline 16.51 & 16.51 & 0.28 & 0.35 & 8.97 & 100.47 \\
\hline 82.55 & 33.02 & 0.81 & 0.32 & 8.06 & 139.67 \\
\hline 115.58 & 33.02 & 0.89 & 0.32 & 7.98 & 143.77 \\
\hline 181.62 & 33.02 & 1.00 & 0.31 & 7.88 & 149.07 \\
\hline 214.64 & 33.02 & 1.01 & 0.31 & 7.87 & 149.61 \\
\hline 280.68 & 33.02 & 1.04 & 0.31 & 7.85 & 150.70 \\
\hline 313.70 & 33.02 & 1.05 & 0.31 & 7.84 & 151.25 \\
\hline 412.77 & 33.02 & 1.07 & 0.31 & 7.82 & 152.35 \\
\hline 492.84 & 21.75 & 2.05 & 0.29 & 7.26 & 186.58 \\
\hline 536.35 & 17.57 & 3.61 & 0.27 & 6.77 & 222.80 \\
\hline
\end{tabular}

TABLE 6: Results of the particle size analysis test of the sliding zone soil.

\begin{tabular}{lcc}
\hline Position & Friction coefficient & Cohesion $(\mathrm{kPa})$ \\
\hline Above water & 0.606 & 118 \\
Under water & 0.485 & 36 \\
\hline
\end{tabular}


TABLe 7: Calculation parameters of the landslide.

\begin{tabular}{lccc}
\hline No. & Name & Unit weight $\gamma\left(\mathrm{KN} / \mathrm{m}^{3}\right)$ & $f$ \\
\hline 1 & Sliding zone (above water) & 21.5 & 0.606 \\
2 & Sliding zone (under water) & 22.5 & 0.485 \\
3 & Bedrock (above water) & 27.2 & 0.575 \\
4 & Bedrock (under water) & 27.5 & 0.46 \\
\hline
\end{tabular}

TABLE 8: Calculation conditions of the landslide.

\begin{tabular}{lcccc}
\hline Calculation condition & Calculation condition 1 & Calculation condition 2 & Calculation condition 3 & Calculation condition 4 \\
\hline Water level & Natural water level & Normal water level $800 \mathrm{~m}$ & Normal water level $800 \mathrm{~m}$ & Normal water level $800 \mathrm{~m}$ \\
Seismic load & - & - & $0.195 \mathrm{~g}$ & - \\
Collapsed bank & - & - & Collapsed bank $30 \mathrm{~m}$ wide & Collapsed bank $30 \mathrm{~m}$ wide \\
\hline
\end{tabular}

TABLE 9: Overall stability calculation results of the landslide.

\begin{tabular}{lcccc}
\hline Calculation condition & Calculation condition 1 & Calculation condition 2 & Calculation condition 3 & Calculation condition 4 \\
\hline Safety factor K & 1.337 & 1.231 & 1.086 & 1.190 \\
\hline
\end{tabular}

However, after the reservoir impounds water and the leading edge of the slope collapses, it was basically stable under a seismic condition, with low safety reserves.

\section{Engineering Treatment Measures}

6.1. Protection of the Water Level Fluctuation Area. The schematic diagram of water level protection zone is shown in Figure 10. To ensure the stability of the Hejia landslide and prevent instability after bank collapse, the following measures were taken for the water level fluctuation area:

(1) Range of protection elevation: EL790 EL810.

(2) The slope and walkway within EL790 EL810 were poured with concrete with a thickness of $80 \sim 30 \mathrm{~cm}$ and a grade of C20. Then the surfaces were laid with reinforcing meshes with a diameter of $18 \mathrm{~mm}$ and a spacing of $25 \mathrm{~cm}$.

(3) The gravel soil slope within EL790 EL810 was laid with anchor rods with $28 \mathrm{~mm}$ diameter, $2 \mathrm{~m}$ spacing, and $4.5 \mathrm{~m}$ length, and $50 \mathrm{~cm}$ of the rod was exposed; the debris slope was installed with soil nails which were $48 \mathrm{~mm}$ in diameter and $18 \mathrm{~m}$ in length, and $50 \mathrm{~cm}$ was exposed.

(4) The slope was laid with PVC drainage pipes with a diameter of $50 \mathrm{~mm}$ and a spacing of $2 \mathrm{~m}$, which extended into the slope and were wrapped with geotextile.

(5) Besides concrete and soil nails applied for the surface gravel soil in the shallow part, a row of $1,000 \mathrm{KN}$ unbonded prestressed anchor cables, with a length of $30 \sim 40 \mathrm{~m}$, a spacing of $6 \mathrm{~m}$, and a depth of entering rock of not less than $5 \mathrm{~m}$, were laid at EL795 and EL800 to ensure the overall stability. than EL790 m has problems as follows: During low-head operation of the reservoir, the slope is scoured by waves. After the water level rises, the slope immerses in the water for a long time. Once it becomes saturated, the bank may collapse. This may affect the stability of the protection area. Therefore, it must be treated.

According to geological information and relevant literature, the underwater angle of repose of the slope colluvial deposits is $28 \sim 32^{\circ}$. The underwater angles of repose for most slope colluvial deposits in the lower part of the protection area were greater than $29 \sim 33^{\circ}$, with an average of $31^{\circ}$. When the reservoir stores water, the lower part may collapse and form a new slope, which would affect the stability of the upper protection area. To prevent this, it was planned to build a gabion retaining wall on the first terrace of the river. After renovation, the angle of the slope would be $30^{\circ}$. As it was close to the angle of repose underwater, the stability of the slope could be ensured.

6.3. Landslide Monitoring. In addition to necessary engineering protection and treatment, relevant prototype monitoring measures were taken to ensure the stability of the Hejia landslide. The detailed scheme was as follows:

(1) Three monitoring longitudinal sections were set, each with four points to monitor surface deformation. Eight working base points were set outside the landslide area to monitor horizontal displacement with the line of collimation method.

(2) Indium measuring lines were laid inside the exploration adits for relative level monitoring. Hydrostatic levelling points were set along the adit line to measure the vertical displacement. The deepest point was penetrated into the stable rock mass at the bottom of the landslide.

(3) Inclinometer pipes were buried in existing exploration bore-holes for deformation monitoring of the deep sliding mass. 


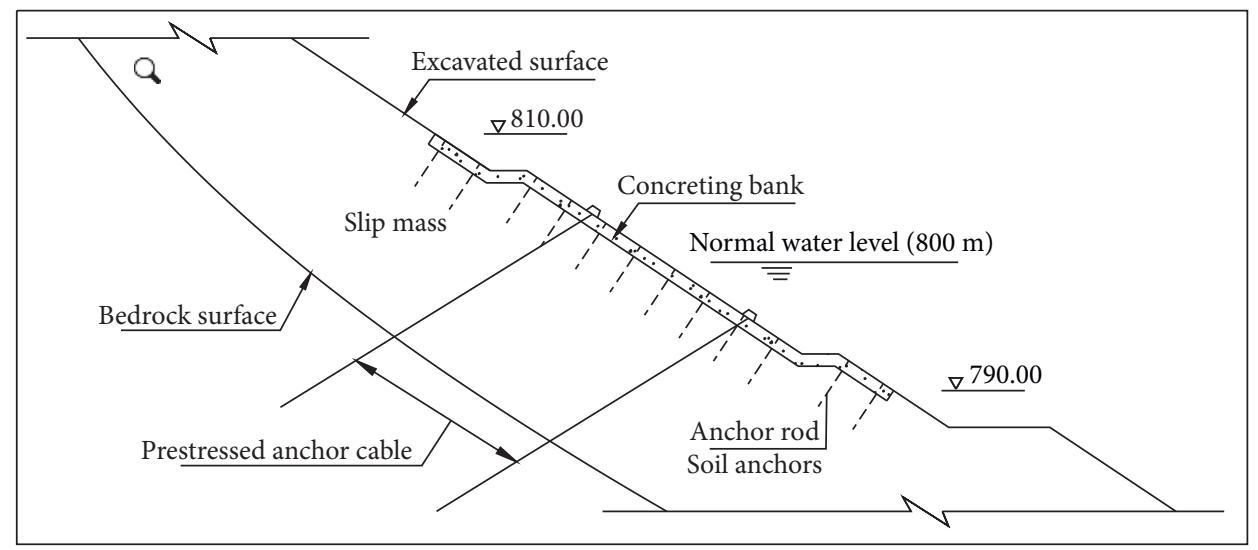

Figure 10: Schematic diagram of water level protection zone.

\section{Conclusion}

Through the field survey and experimental study, this paper has analyzed the structural characteristics of the Hejia landslide and its formation mechanism; moreover, it has proposed engineering measures to enhance the stability of the slope as the water level of the reservoir fluctuated. The conclusions are as follows:

(1) The Hejia landslide is located in the reservoir area of a hydropower station. Its volume is as large as $2,350 \times 10^{4} \mathrm{~m}^{3}$; as a super large-scale landslide, it is formed by long-term sliding and bending deformation. The outside layer of the slope consists of high, steep, and layered hard rock and the sliding zone is comprised of layered soft rock.

(2) The formation mechanism of the landslide is as follows: (1) Hard, soft, high, steep, and layered slope has provided structural conditions for the formation of the sliding mass; (2) thick-layered weak rock zone has provided material conditions for the formation of the sliding surface; (3) free face conditions have provided displacement space for the separation and disintegration of the sliding mass.

(3) When the reservoir impounds water, the slope toe will be immersed under the water, which may decrease the safety factor, though the factor still meets the requirement.

(4) When the reservoir impounds water, the overall stability of the slope can be assured but the slope toe may collapse, so related engineering measures should to be taken.

(5) According to the operation monitoring data of the past multiple years, the landslide has been stable since the engineering measures were taken. This proves that the engineering treatment is reasonable.

\section{Data Availability}

All data, models, and codes generated or used during the study appear in the submitted article.

\section{Conflicts of Interest}

The authors declare that they have no conflicts of interest.

\section{Acknowledgments}

This project was supported by the National Natural Science Foundation of China (Grant nos. U1965107 and 51979218) and Natural Science Foundation of Shaanxi Province (Grant no. 2018JM5118).

\section{References}

[1] Z. Li, "Landslide induced by water mist at Longyangxia hydropower station," Dam and Safety, vol. 17-20, pp. 29-56, 2001.

[2] L. S. Xing and T. Li, "Influence of flood discharge and rain mist on operation of hydropower station and countermeasures," Dam and Safety, vol. 57, pp. 1-4, 2010.

[3] X. L. Tang and Q. Gao, "Characteristics and slope control of manwan left bank landslide," in Proceedings of the 2nd $\mathrm{Na}$ tional Geotechnical and Engineering Conference, vol. 1, 2006.

[4] J. Wang, Study on Deformation Evolution Mechanism of Guobu Bank Slope in Front of Laxiwa Hydropower Station in Yellow River, Chengdu University of Technology, Chengdu, China, 2011.

[5] Z. J. Yi, R. Q. Huang, H. Y. Wu, S. He, J. Yang, and L. Zhou, "Research on formation mechanism of Tanggudong landslide," Journal of Engineering Geology, vol. 24, no. 6, pp. 1072-1079, 2016.

[6] Z. W Dai, "Study on deformation and instability mechanism of outang landslide in the three Gorges reservoir area," 2016, https://www.mdpi.com/2071-1050/12/16/6427/pdf.

[7] B. Yuan, Z. Li, Z. Su, Q. Luo, M. Chen, and Z. Zhao, "Sensitivity of multistage fill slope based on finite element model," Advances in Civil Engineering, vol. 2021, Article ID 6622936, 13 pages, 2021.

[8] J. Guo, "Study on process control of landslide promoting landslide treatment under the action of reservoir water," 2014.

[9] Z. G. Yu, Study on the Influence of Reservoir Water Level Fluctuation on the Deformation and Stability of Rocky Bank Slope, Chongqing University, Shapingba, China, 2017.

[10] Z. Y. Wei, J. Song, and Y. J. Cheng, "Effect of water level fluctuation on stability of Hejiapo landslide in Fengjie Reservoir area," Journal of Forests, vol. 48, no. 4, pp. 118-123, 2017. 
[11] B. X. Yuan, Z. H. Li, Y. M. Chen et al., "Mechanical and microstructural properties of recycling granite residual soil reinforced with glass fiber and liquid-modified polyvinyl alcohol polymer," Chemosphere, vol. 268, Article ID 131652, 2021.

[12] R. A. Wu, "Reactivation mechanism and risk assessment of ancient landslides in the upper reaches of minjiang river," 2019.

[13] J. F. Xiao, Y. A. Li, Y. Hu, S. Zhang, and J. M. Cai, "Model tests on deformation characteristics of ancient bank landslide under water level fluctuation and rainfall," Rock and Soil Mechanics, vol. 42, no. 2, p. 10, 2021.

[14] B. Yuan, Z. Cai, M. Lu, J. Lv, Z. Su, and Z. Zhao, "Seepage analysis on the surface layer of multistage filled slope with rainfall infiltration," Advances in Civil Engineering, vol. 2020, Article ID 8879295, 13 pages, 2020.

[15] L. L. He, L. Zhou, and Y. Liang, "Simplified analysis of bank slope stability under the influence of water level sudden drop," Hydro-Science and Engineering, vol. 130, no. 3, pp. 16-24, 2021.

[16] H. Yang, M. G. Tang, and Q. Xu, "Study on seepage hysteresis of landslide accumulation in the three gorges reservoir area under the fluctuation of reservoir water level," Water Resources and Hydropower Technology, vol. 51, no. 12, pp. 9-15, 2020, https://www.mdpi.com/2071-1050/12/16/6427/pdf.

[17] B. Yuan, Z. Li, Z. Zhao, H. Ni, Z. Su, and Z. Li, "Experimental study of displacement field of layered soils surrounding laterally loaded pile based on transparent soil," Journal of Soils and Sediments, vol. 21, no. 9, pp. 3072-3083, 2021. 